\title{
The response of hydrophyte growth forms and plant strategies to river restoration
}

\author{
Frauke Ecke • Seppo Hellsten • Jan Köhler • Armin W. Lorenz • \\ Jaana Rääpysjärvi • Sabine Scheunig • Joel Segersten • \\ Annette Baattrup-Pedersen
}

Received: 6 February 2015/Revised: 21 November 2015/Accepted: 29 November 2015/Published online: 16 December 2015

(C) The Author(s) 2015. This article is published with open access at Springerlink.com

\begin{abstract}
Evaluating ecological responses to restoration is important for assessing the success of river restorations. We evaluated the response of species richness and diversity of aquatic macrophyte (hydrophyte, instream aquatic plant) growth forms and strategies (Grime's CSR strategies; C competitive, S stress tolerant, $\mathrm{R}$ ruderal) in 10 small- and 10 largescale river restoration projects in nine European countries. Restoration had no effect on total richness and diversity but significant effects if specific growth
\end{abstract}

Electronic supplementary material The online version of this article (doi:10.1007/s10750-015-2605-6) contains supplementary material, which is available to authorized users.

Guest editors: Jochem Kail, Brendan G. McKie, Piet F. M. Verdonschot \& Daniel Hering / Effects of hydromorphological river restoration

\section{F. Ecke $\cdot$ J. Segersten}

Department of Aquatic Sciences and Assessment, Swedish University of Agricultural Sciences (SLU), P.O. Box 7050, 75007 Uppsala, Sweden

\section{F. Ecke $(\bowtie)$}

Department of Wildlife, Fish and Environmental Studies, Swedish University of Agricultural Sciences (SLU), 90183 Umeå, Sweden

e-mail: frauke.ecke@slu.se

S. Hellsten · J. Rääpysjärvi

Freshwater Centre, Finnish Environment Institute SYKE, P.O. Box 413, University of Oulu, 90014 Oulu, Finland forms and plant strategies were considered. Results indicated that restoration caused an increase in the richness and diversity of submerged and a decrease in the proportion of competitive species. Responses were especially pronounced in relatively small widening projects in gravel-bed mountain rivers but not in relatively large restoration projects in sand-bed lowland rivers. Moreover, flow restoration increased the richness and diversity of floating-leaved species. In rivers with a high proportion of wetlands and waterbodies in the catchment, restoration increased the abundance of competitive plants. These results highlight that river and catchment properties need to be considered when evaluating river restoration projects. We suggest hydrophyte growth forms and plant strategies as suitable response variables to assess the effect of river restoration projects.

\section{J. Köhler · S. Scheunig}

Department for Ecosystem Research, Leibniz-Institute of Freshwater Ecology and Inland Fisheries (IGB), Müggelseedamm 301, 12587 Berlin, Germany
A. W. Lorenz
Department of Aquatic Ecology, University of Duisburg- Essen, Universitätsstr. 5, 45141 Essen, Germany
A. Baattrup-Pedersen
Department of Bioscience, Aarhus University, Vejlsøvej
25, P.O. Box 314, 8600 Silkeborg, Denmark 
Keywords CSR - Grime - Aquatic macrophytes ·

Life form - Ecological indicator - Restoration success

\section{Introduction}

The degradation of rivers and streams is an increasing problem worldwide jeopardizing their ecological quality and their provisional services (Gleick, 2003). For example, the partial loss of aquatic macrophytes (Steffen et al., 2013) not only has severe consequences for macrophyte diversity but might also have cascading ecological effects due to the macrophytes' importance as habitat for other organism groups (Heck Jr. \& Crowder, 1991; Strayer \& Malcom, 2007; Basińska et al., 2014). Furthermore, aquatic macrophytes also function as ecosystem engineers (Asaeda et al., 2010; O'Hare et al., 2011) and influence river processes such as metabolism and nutrient cycling (Tabacchi et al., 1998).

A large number of river restoration projects have been initiated to reverse river ecosystem degradation. These projects vary in restoration type, spatial extent and characteristics at the local and catchment scale. Therefore, different responses can be expected depending on the chosen restoration approach as well as on river and catchment characteristics. However, generally, we expect river restoration to increase habitat heterogeneity, i.e. structural complexity, and therefore to favour species richness and diversity sensu the 'habitat heterogeneity hypothesis' (e.g. Simpson, 1949; MacArthur \& Wilson, 1967). An extensive review of 78 restoration projects focusing on macroinvertebrates has however shown that restored habitat heterogeneity per se may not restore biodiversity (Palmer et al., 2010). On the other hand, comparisons between degraded and non-degraded stream reaches indicate that river restorations can favour vegetation typical for non-degraded reaches. Positive restoration effects were reported for different aquatic plant growth forms including helophytes (emerging species), elodeids (submerged species without floating leaves) and lemnids (floating species) (Lorenz et al., 2012). In a recent meta-analysis by Kail et al. (2015), macrophytes showed the most pronounced response to river restoration among the studied organism groups, especially in widening projects. Different responses to river restoration can be due to interference with other stream processes. Time after restoration is an important predictor of macrophyte responses to restoration (Baattrup-Pedersen et al., 2000; Kail et al., 2015) and any potential response might be blurred by a too short time span between restoration and follow-up study, for the biota to adjust to. Also, river morphology and upstream riparian land use might influence our ability to detect effects of river restoration (Lorenz \& Feld, 2013).

Plant strategies can be classified into competitive (C), stress (S) and ruderal/disturbance (R) strategies (Grime, 1974, 1977, 1979, 1987, 1988). According to Grime's model, plant species respond to two controlling factors, namely stress and disturbance (Grime, 1977). The model has extensively been applied, tested and also questioned (e.g. Murphy et al., 1990; Ecke \& Rydin, 2000; Craine, 2005).

Here, we evaluated the restoration response by calculating effect sizes (difference between restored and degraded) of species richness and diversity of hydrophyte growth forms (bryophytes, elodeids, nymphaeids and lemnids) and of macrophyte plant strategies (Grime's CSR strategies) in 20 European river restoration projects. We chose to work with growth forms and strategies instead of only richness and diversity of hydrophytes for two reasons. First, the distribution range of many species does not cover all restoration projects. Hence, potential absence of certain species might rather reflect natural distributions than restoration effects. Second, analysing growth forms and strategies might provide deeper insight into the functional response of macrophytes to river restoration than analyses at the species level.

We expect flow-sensitive elodeids to be favoured by restoration measures such as removal of bank fixation, remeandering, and widening. The flow-sensitive growth forms nymphaeids and especially lemnids should be adversely affected at sites with e.g. flow restoration since they are generally sensitive to water level fluctuations (Mjelde et al., 2013). The floating leaves of nymphaeids will, depending on timing, not be able to withstand strong water flow and high amplitudes in water level (Paillisson \& Marion, 2011). Lemnids as non-rooted plants will be flushed away during high-flow periods (Hellsten, 2001). In addition to growth forms, we also expect the proportion of different plant strategies in the communities to be affected by restoration. According to Grime's model, we expect the proportion of competitive species (C) to 
dominate at sites with low disturbance incidence. Stress-tolerant (S) species are typical for habitats with challenging environmental conditions and ruderal species (R) for ephemeral habitats (Grime et al., 2007). Hence, river restoration measures resulting in instable conditions and potentially in new and exposed habitats, e.g. due to increased water level fluctuations, should favour the proportion of ruderal species, whereas that of stress-tolerant species might be favoured for example by light limitation and increased water depth. In addition and in line with Lorenz et al. (2012), Lorenz \& Feld (2013) and Kail et al. (2015), we expect potential restoration type-specific responses to be obscured by differences in river and catchment characteristics.

\section{Materials and methods}

Study sites and environmental data

Our study comprised 10 small-scale and 10 large-scale river restoration projects distributed in nine European countries (Austria, Czech Republic, Denmark, Finland, Germany, Poland, Sweden, Switzerland, and The Netherlands). Ten pairs of corresponding large and small restoration projects were investigated to address the role of restoration extent for river restoration effects. The restoration effect was quantified by comparing each of the 20 restored river sections to a nearby upstream non-restored and degraded section. The large restoration projects represented good-practice examples either targeting medium-sized lowland rivers or medium-sized mountain rivers. The majority of the mountain rivers investigated were restored by removing bed and bank fixation, flattening river banks, and partly widening the cross-section (referred to as widening in the following). In the lowland rivers, remeandering and reconnecting oxbows were the most prominent measures besides increasing groundwater levels for restoring wetlands. Moreover, instream measures like large wood and boulder placement have been applied. Restoration characteristics were gathered at the scale of (i) individual projects (type of restoration, restoration length, project size, and time since restoration), (ii) rivers (altitude, slope, discharge, substrate type, hydromorphological variables, and concentrations of total organic carbon, ammonium and phosphate) and (iii) catchment (percentage cover of different Corine 2006 land cover classes, artificial surface, agricultural areas, forest and semi-natural areas, wetlands and water bodies). Detailed information on these characteristics is given in the introduction paper of this issue (Muhar et al.). Hydromorphological properties of the study sites are presented by Poppe et al. (this issue) and in Table S1. Project size was calculated as restoration length $(\mathrm{m})$ divided by mean river width $(\mathrm{m})$. Concentrations of total organic carbon (TOC), ammonium and phosphate were either measured during the field surveys or taken from national databases for the respective rivers.

\section{Biological data}

Aquatic macrophytes were surveyed during the peak of the growing season (July to mid-September) applying an EU Water Framework Directive (WFD) compliant sampling protocol (Schaumburg et al., 2004). One reach of $200 \mathrm{~m}$ length was sampled in each of the restored and degraded sections by wading in a zigzag manner across the channel and walking along the riverbank. In non-wadable areas, the river bottom was examined with a rake (on a long pole or at the end of a rope) to reach the macrophytes. All macrophyte species were recorded and identified to species level except some specimens of Alopecurus spp., Callitriche spp., Carex spp., Rumex spp., Sparganium spp., and Veronica spp. that could only be identified to the genus level. The survey included all submerged, free-floating, amphibious and emergent angiosperms and bryophytes (see Appendix-Supplementary Material). In addition, we sampled plants that were attached or rooted in parts on the river bank and that were likely to be submerged for most of the year. The abundance of each species as percentage cover was recorded according to a 5-point scale: $1=1-5 \%$; $2=5-25 \% ; 3=25-50 \% ; 4=50-75 \%$ and $5=$ $75-100 \%$.

\section{Data analysis}

Some of the growth forms were represented by only few species. We therefore focused on the growth forms elodeids (rooted or non-rooted, submerged without floating leaves), bryophytes, lemnids (freefloating) and nymphaeids (rooted with floating leaves) according to Mäkirinta (1978) and Andersson (1999) (see Appendix-Supplementary Material). Isoetids 
were excluded from all analyses due to few occurrences. Helophytes (plants living in bank habitats which temporarily dry up) do not meet the hydrophyte definition and were therefore excluded from the analyses of growth forms but were included in the analyses of plant strategies (see below).

As measures of species diversity, we calculated species richness and Shannon diversity $\left(\mathrm{H}^{\prime}\right.$; from here on referred to as diversity) (Krebs, 1989) separately for the group of hydrophytes and all growth forms. After calculating diversity, all missing values (due to the absence of species) were replaced by zero. This implied that the diversity at sites without species and at sites with only one species received the same value. For each site, we calculated the mean proportion of CSR strategies in the plant community based on the presence data of all species, except bryophytes since CSR strategies are only available for a few bryophyte species. Plant strategies were taken from Klotz et al. (2002) and Grime et al. (2007) (see AppendixSupplementary Material). The strategies of species with multiple and/or combined strategies were assigned by calculating the percentage of the respective strategies. For example, Iris pseudacorus L., a C/CSR species (Grime et al., 2007) was classified as $50 \% \mathrm{C}, 25 \% \mathrm{~S}$ and $25 \% \mathrm{R}$. Due to missing information on CSR plant strategies for some species, we excluded some species from the analysis on plant strategies (see Appendix-Supplementary Material).

The effect of restoration on species richness and diversity as well as on the percentage of the different plant strategies was quantified by the difference between the restored and corresponding degraded control site ( $\mathrm{R}$ minus $\mathrm{D}$ ). We termed this difference as the effect size.

To reduce the number of hydromorphological predictor variables (see Poppe et al., this issue) to a few components (PC), we performed a principal component analysis (PCA) (Sharma, 1996) and used factor loadings $>10.71$ for the interpretation. PC1 explained 30.7 and PC2 $17.5 \%$ of the variance in the hydromorphological variables. PC1 represented hydromorphological variables at the reach scale and PC2 represented hydromorphological variables at the mesohabitat scale (see Poppe et al., this issue, for more details on the hydromorphological variables and Table S1 for the result of the PCA). To analyse the overall relationship between the species data (effect of restoration on hydrophytes growth forms and plant strategies) and environmental variables (catchment, river and project characteristics, PCs of hydromorphological variables of first PCA), we performed a second PCA. The PCA as an indirect gradient analysis was based on the species data, with species scores divided by standard deviation, and species data centred and standardized. The environmental variables were used as supplementary variables by making a post hoc regression between the environmental variables and the PCs (see ter Braak \& Smilaur, 2002). We only interpreted principal components (PCs) with eigenvalues $>0.1$. Variables with loadings $>|0.7|$ were used for the interpretation of the PCs. We evaluated effect size in relation to the size of the restoration (small or large), main type of restoration measure (widening, remeandering, instream measures, or flow restoration), river type (mountain or lowland) and main substrate type (gravel or sand). These main characteristics are described in Muhar et al. (this issue). Differences in effect size within classes (e.g. restoration measures, restoration size) were tested with Friedman's ANOVA test and differences between classes with the Kruskal-Wallis test (Zar, 1996). Whether effect size differed significantly from zero was tested with the sign test (Zar, 1996). Finally, we correlated effect size to restoration characteristics at the level of individual restoration projects, rivers and catchments (see above and Muhar et al., this issue) using Spearman rank order correlation coefficients (Zar, 1996). All statistical analyses were performed in Statistica (StatSoft, 2013) except the PCA on species and environmental data, which was done in the CANOCO statistical software (ter Braak \& Smilaur, 2002).

\section{Results}

In total, we found 143 species of which 70 were hydrophyte species with a median of seven hydrophyte species per site (range 0-16). Bryophytes were the most species-rich growth form (31 species; excluding the bryophyte Riccia fluitans L.), followed by elodeids (24 species), nymphaeids (eight species), lemnids (six species; including the bryophyte $R$. fluitans L.) and isoetids (one species). In total, 73 helophyte species were found (see Appendix-Supplementary Material).

The restored and degraded control sites were generally characterized by species with high 
proportion of competitive (C) (mean $51.5 \pm \mathrm{SD}$ $18.0 \%$ ) and ruderal (R) strategies (mean $30.6 \pm$ SD $10.8 \%$ ) and only to a lesser degree by species with stress-tolerant (S) strategies (mean $17.9 \pm$ SD 12.8\%; Fig. 1).

\section{General species responses}

The overall relationship between the effect of restoration on helophytes and the environmental variables was rather weak but revealed some trends. The PCA explained about half of the variance of the biological effect sizes (Fig. 2). Most effect sizes on plant strategies, and richness and diversity of growth forms showed a similar response, except for the competitive plant strategy and bryophyte richness and diversity (Fig. 2). Moreover, the response was more similar for the effect sizes on richness and diversity, i.e. within different growth forms compared to between growth forms. The overlay of supplementary variables indicated that restoration effects on hydrophytes were especially high in older projects in the forested mountain rivers. These projects were characterized by high altitude, discharge, and slope that created high mesohabitat diversity in contrast to larger projects in agricultural lowland rivers that enhanced reach-scale hydromorphology (Fig. 2). However, the environmental variables were only

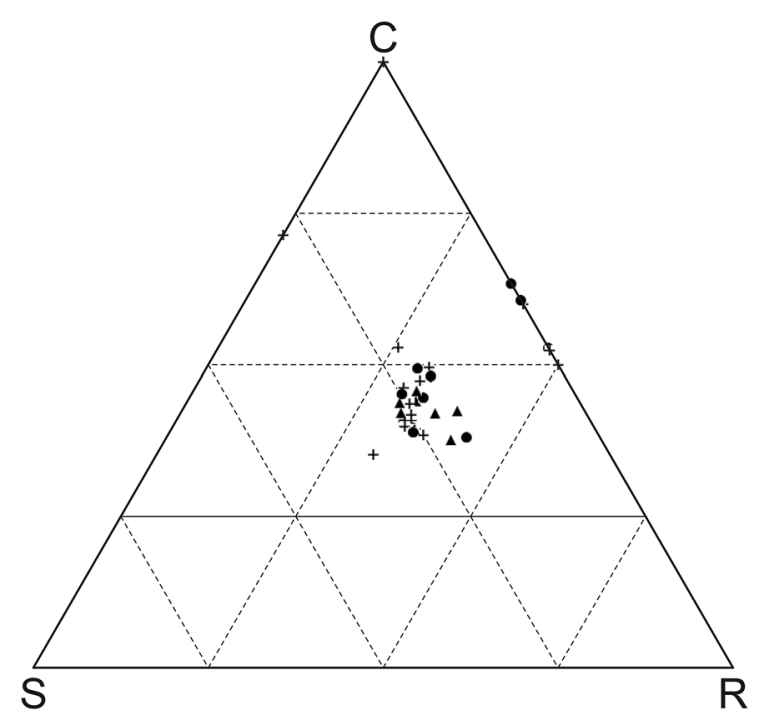

Fig. 1 Mean proportion of CSR plant strategies at degraded (crosses, $n=20$ ), small-scale restoration (filled triangles, $n=10$ ) and large-scale restoration (filled circles, $n=10$ ) sites

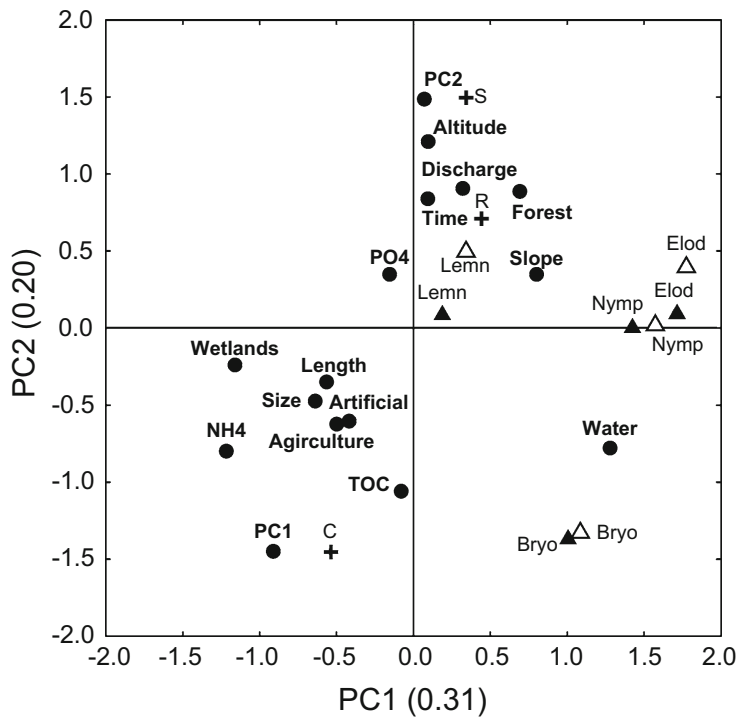

Fig. 2 Biplot of the first two principal components (PCs) of the environmental (bold, filled circles) and species data. Eigenvalues of the two PCs are given in parentheses after the respective PCs. Open and closed triangles denote species richness and diversity, respectively. Crosses denote the plant strategies competitive (C), stress tolerant (S) and ruderal (R). Environmental variables represent those given in Tables 1 and 2. PC1 and PC2 represent the first two PCs of the PCA on the hydromorphological variables (see Table S1). Bryo, bryophytes; Elod, elodeids; Lemn, lemnids; Nymp, nymphaeids

weakly related to the PCA axis (t-values of regression coefficients were $<2.1$ ). The small-scale and largescale restoration sites in the different countries behaved rather similar, except in Austria, Switzerland and Germany (Online Resource 2).

Responses to size of restoration projects

The effect size of neither total richness nor total diversity of hydrophytes differed from zero at small- or large-scale restoration sites or when combining all sites (Sign test, small-scale restoration sites, richness: $z=-0.35, n=10, P=0.72$, diversity: $z=-0.35$, $n=10, P=0.72$; large-scale restoration sites, richness: $z=0.35, n=10, P=0.72$, diversity: $z=0.00$, $n=10, P=1.00$ ). However, focusing on hydrophyte growth forms revealed significant patterns. The increase in elodeid species richness and diversity differed from zero at sites with small-scale restoration sites (Sign test, $z=2.04, n=10, P<0.05$ and $z=2.04, n=10, P<0.05$, respectively) and all restoration sites combined, (Sign test, $z=2.58$, 
$n=20, P<0.01$ and $z=2.22, P<0.05$, respectively) (Fig. 3). Moreover, the decrease in the proportion of competitive species at small-scale and all restoration sites combined differed from zero (Sign test, $z=2.1, n=10, P<0.05$ and $z=2.01, n=20$, $P<0.05$, respectively) (Fig. 4). At small-scale restoration sites, also the increase in the proportion of stress-tolerant species differed significantly from zero (Sign test, $z=2.21, n=10, P<0.05$ ) (Fig. 4).

The response of species richness but not of diversity differed among growth forms at small-scale restored sites (species richness; ANOVA $\chi_{(n=10, d f=3)}^{2}=9.94$, $P<0.05)$ and also when combining all restored sites
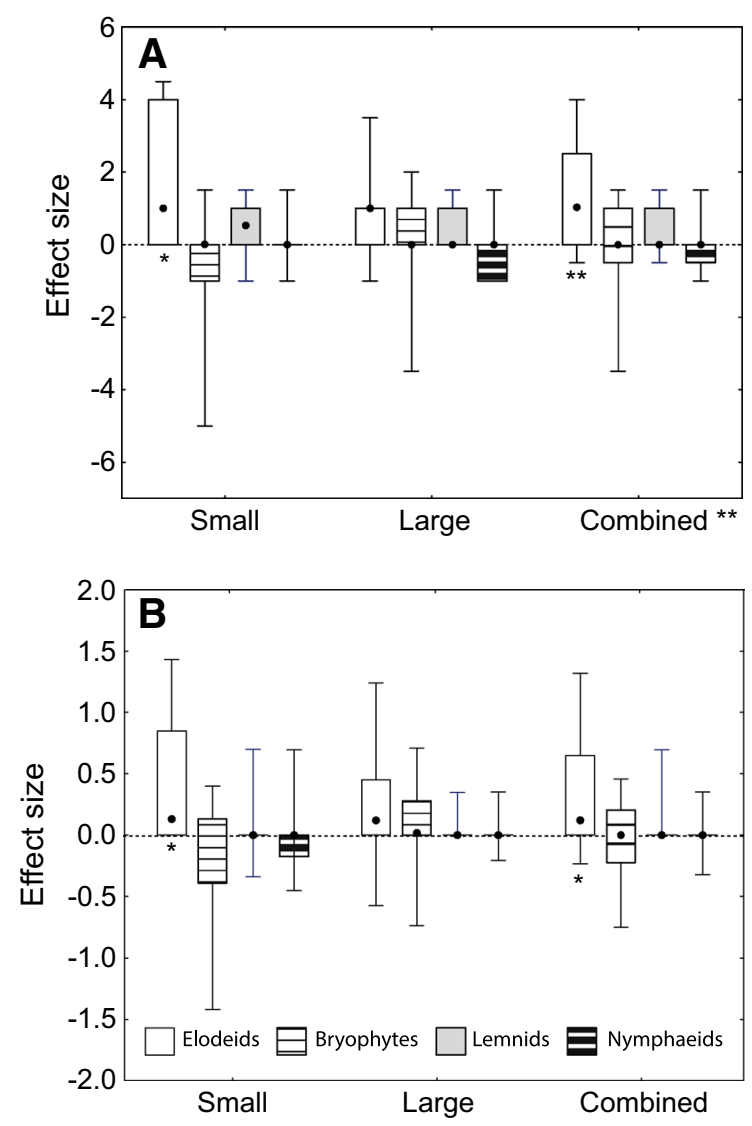

Fig. 3 Median effect size (difference between restored and degraded) of the species richness (A) and diversity (B) of hydrophyte growth forms at small-scale $(n=10)$ and largescale $(n=10)$ restoration sites, as well as at all restoration sites combined $(n=20)$. Boxes represent 25 and 75 percentiles and whiskers 10 and 90 percentiles, respectively. Asterisks to the right of the restoration size class indicate significant differences $(P<0.05)$ among growth forms for the respective restoration size class. Asterisks below box-plots indicate that the effect size differed significantly from zero $(* P<0.05$, $* * P<0.01)$

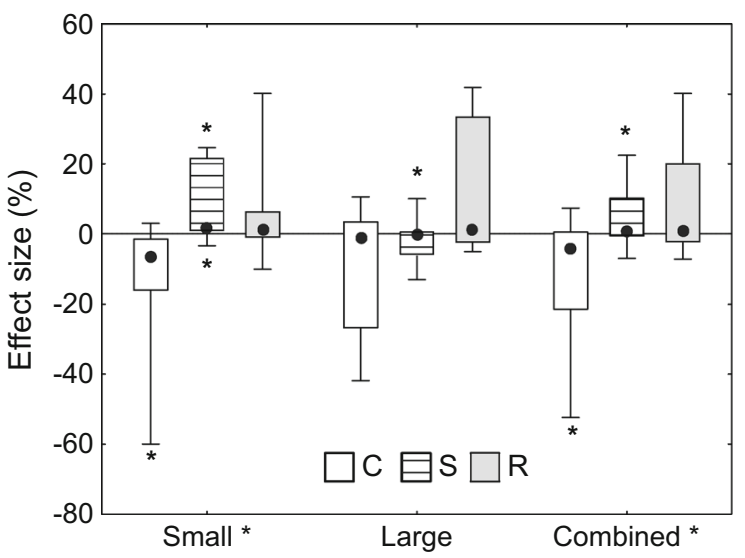

Fig. 4 Median effect size (difference between restored and degraded) of CSR plant strategies at small-scale $(n=10)$, largescale $(n=10)$ restoration sites and at all restoration sites combined $(n=20)$. Boxes represent 25 and 75 percentiles and whiskers 10 and 90 percentiles, respectively. Asterisks to the right of the restoration size class indicate significant differences $(P<0.05)$ among strategies for the respective restoration size class. Asterisks below box-plots indicate that the effect size differed significantly from zero $(P<0.05)$. Asterisks above box-plots indicate that the effect size for a strategy differed between restoration size classes $(P<0.05)$

(species richness, ANOVA $\chi_{(n=20, d f=3)}^{2}=15.23$, $P<0.01)$ but not at large-scale restored sites (species richness, ANOVA $\left.\chi_{(n=10, d f=3)}^{2}=6.11, P>0.05\right)$ (Fig. 3). Combining all hydrophyte species, the response of neither richness nor diversity differed between small and large-scale restoration sites (Sign test, $z=-0.32, n=10, P>0.05$ and $z=-0.32$, $n=10, P>0.05$, respectively). A closer look at the level of growth forms revealed that differences between restored and degraded were positive for richness of elodeids (increase by four species; 75 percentile) and lemnids (increase by one species; 75 percentile) in small-scale restored sites and also when combining all restored sites, whereas bryophyte richness showed a negative response (minus one species; 75 percentile) at small-scale restored sites (Fig. 3).

Focusing on plant strategies revealed differences in the proportion of CSR strategies between restored and degraded sites for small-scale and all restorations combined. At small-scale restoration sites and at all restoration sites combined, the response of the proportion of strategies varied among strategy types (ANOVA $\chi_{(n=10, d f=2)}^{2}=7.40, \quad P<0.05$ and ANOVA $\chi_{(n=20, d f=2)}^{2}=6.30, P<0.05$, respectively). The proportion of $\mathrm{S}$ strategies in the plant communities was 
higher in small-scale restoration projects but lower in large-scale restoration projects (Kruskal-Wallis test, $\left.H_{(1, n=20)}=6.61, P<0.05\right)$ (Fig. 4).

Only the diversity of nymphaeids was negatively correlated with project size (Table 1), and neither the response of growth form nor plant strategy was correlated with time after restoration (Tables 1,2).

\section{Responses to restoration type}

The restoration type did not affect the response of species richness and diversity of hydrophytes if all growth forms were pooled (results not shown). However, at sites that were widened, the species richness of elodeids showed a positive response (Sign test, $z=2.48, P<0.05$ ) (Fig. 5). Widening caused a significant decrease of the share of competitive species (Sign test, $z=2.67, n=9, P<0.01$ ) (Fig. 6A). As a consequence, the share of stress-tolerant and ruderal species increased, resulting in significant differences between the plant strategies in the widening projects (ANOVA $\left.\chi_{(n}^{2}=9, \quad d f=2\right)=14.00, \quad P<0.001$ ) (Fig. 6A). No such changes were observed for the other restoration types, and hence, the effect of restoration on the share of competitive species was solely due to widening (Kruskal-Wallis test, $\left.H_{(3, n=18)}=12.36, P<0.01\right)($ Fig. 6A).

At sites with widening as the main restoration measure, effect sizes of richness but not of diversity differed among growth forms (ANOVA $\left.\chi_{(n=9,}^{2} \quad d f=3\right)=9.48, \quad P<0.05$ and ANOVA $\left.\chi_{(n}^{2}=9, \quad d f=3\right)=5.16, P>0.05$, respectively)

Table 1 Correlation coefficients (Spearman rank order) between the effect size (difference between restored and degraded) of species richness (SR) and diversity (D) of different growth forms and predictor variables

\begin{tabular}{|c|c|c|c|c|c|c|c|c|c|c|}
\hline \multirow[t]{2}{*}{ Predictor } & \multicolumn{2}{|c|}{ Hydrophytes } & \multicolumn{2}{|c|}{ Elodeids } & \multicolumn{2}{|c|}{ Bryophytes } & \multicolumn{2}{|c|}{ Lemnids } & \multicolumn{2}{|c|}{ Nymphaeids } \\
\hline & SR & $\mathrm{D}$ & SR & $\mathrm{D}$ & SR & $\mathrm{D}$ & SR & $\mathrm{D}$ & SR & $\mathrm{D}$ \\
\hline \multicolumn{11}{|l|}{ Project scale } \\
\hline Restoration length $(\mathrm{km})$ & -0.07 & -0.31 & 0.05 & 0.18 & -0.05 & 0.01 & 0.12 & 0.25 & -0.07 & -0.27 \\
\hline Project size ${ }^{\mathrm{a}}$ & -0.00 & 0.20 & -0.17 & 0.01 & -0.09 & -0.04 & -0.03 & 0.21 & -0.29 & -0.50 \\
\hline Time after restoration (years) & -0.11 & -0.15 & -0.05 & -0.19 & 0.02 & -0.04 & -0.03 & -0.18 & 0.23 & -0.02 \\
\hline \multicolumn{11}{|l|}{ River scale } \\
\hline Altitude (m) & 0.15 & 0.19 & 0.31 & 0.06 & 0.09 & 0.03 & 0.23 & 0.12 & 0.19 & 0.08 \\
\hline Slope $(\%)$ & 0.06 & 0.10 & 0.22 & 0.05 & -0.07 & -0.16 & -0.07 & -0.31 & 0.47 & 0.57 \\
\hline Discharge $\left(\mathrm{m}^{3} \mathrm{~s}^{-1}\right)$ & 0.28 & 0.14 & 0.41 & 0.39 & 0.13 & 0.13 & 0.35 & 0.12 & 0.29 & 0.10 \\
\hline TOC $\left(\mathrm{mg} \mathrm{l}^{-1}\right)$ & 0.15 & 0.12 & -0.37 & -0.21 & -0.08 & -0.13 & -0.07 & 0.00 & -0.13 & 0.14 \\
\hline Ammonium $\left(\mathrm{mg} \mathrm{l}^{-1}\right)$ & 0.08 & 0.06 & -0.16 & 0.04 & -0.23 & -0.20 & 0.05 & 0.20 & -0.44 & -0.40 \\
\hline Phosphate $\left(\mu \mathrm{g} \mathrm{l}^{-1}\right)$ & 0.04 & 0.34 & -0.15 & -0.01 & 0.00 & 0.07 & 0.50 & 0.50 & -0.40 & -0.42 \\
\hline Hymo PC $1^{\mathrm{b}}$ & -0.06 & -0.06 & -0.55 & -0.61 & -0.04 & 0.02 & -0.09 & -0.03 & -0.40 & -0.33 \\
\hline Hymo PC2 ${ }^{\mathrm{b}}$ & 0.01 & -0.15 & 0.43 & 0.10 & -0.09 & -0.07 & -0.24 & -0.31 & 0.51 & 0.28 \\
\hline \multicolumn{11}{|l|}{ Catchment scale ${ }^{\mathrm{c}}$} \\
\hline Artificial surface $(\%)$ & 0.06 & 0.39 & 0.00 & 0.08 & 0.17 & 0.29 & -0.08 & 0.09 & -0.26 & -0.22 \\
\hline Agricultural areas (\%) & -0.04 & 0.15 & -0.10 & 0.22 & 0.04 & 0.07 & -0.01 & 0.18 & -0.27 & -0.38 \\
\hline Forest, semi-natural areas (\%) & 0.15 & -0.06 & 0.23 & -0.10 & 0.04 & -0.02 & 0.08 & -0.11 & 0.41 & 0.38 \\
\hline Wetlands $(\%)$ & -0.14 & -0.31 & -0.39 & -0.18 & -0.10 & -0.09 & 0.06 & 0.05 & -0.21 & 0.10 \\
\hline Water bodies $(\%)$ & 0.15 & -0.14 & -0.06 & 0.08 & -0.05 & 0.00 & 0.10 & 0.16 & -0.07 & 0.22 \\
\hline
\end{tabular}

Predictor variables are sorted by different scales, viz. project, river and catchment. Significant correlations $(P<0.05)$ are indicated in bold

${ }^{\text {a }}$ Project size was calculated as the ratio between restoration length $(\mathrm{m})$ and restoration width $(\mathrm{m})$

b PC1 was dominated by variables of the hydromorphological survey, e.g. channel geometry, river dynamics, connectivity and riverbed relief. PC2 represented hydromorphological variables at the scale of the mesohabitat, e.g. Shannon diversity for all channel features. For details of the hydromorphological variables, see Poppe et al. (this issue)

c Properties at the catchment scale represent land cover in the catchment 
Table 2 Correlation coefficients (Spearman rank order) between the effect size (difference between restored and degraded) of the CSR strategies and predictor variables. Predictor variables are sorted by different scales, viz. project, river and catchment

\begin{tabular}{|c|c|c|c|}
\hline \multirow[t]{2}{*}{ Predictor } & \multicolumn{3}{|l|}{ Strategy } \\
\hline & Competitive & Stress tolerant & Ruderal \\
\hline \multicolumn{4}{|l|}{ Project scale } \\
\hline Restoration length (km) & 0.39 & 0.15 & $-0.47 *$ \\
\hline Project size ${ }^{\mathrm{a}}$ & 0.39 & 0.03 & -0.34 \\
\hline Time after restoration (years) & -0.42 & 0.16 & 0.10 \\
\hline \multicolumn{4}{|l|}{ River scale } \\
\hline Altitude (m) & $-0.65 * *$ & 0.11 & 0.29 \\
\hline Slope $(\%)$ & & -0.10 & 0.07 \\
\hline Discharge $\left(\mathrm{m}^{3} \mathrm{~s}^{-1}\right)$ & -0.26 & 0.37 & -0.08 \\
\hline TOC $\left(\mathrm{mg} \mathrm{l}^{-1}\right)$ & $0.64 * *$ & -0.44 & -0.08 \\
\hline Ammonium (mg $\left.\mathrm{l}^{-1}\right)$ & -0.03 & 0.26 & 0.05 \\
\hline Phosphate $\left(\mu \mathrm{g} 1^{-1}\right)$ & -0.12 & 0.39 & -0.15 \\
\hline Hymo $\mathrm{PC} 1^{\mathrm{b}}$ & $0.68 * *$ & $-0.57 *$ & $-0.55^{*}$ \\
\hline Hymo PC2 ${ }^{\mathrm{b}}$ & $-0.53 *$ & $0.57 *$ & -0.15 \\
\hline \multicolumn{4}{|l|}{ Catchment scale $^{\mathrm{c}}$} \\
\hline Artificial surface $(\%)$ & -0.06 & 0.12 & 0.04 \\
\hline Agricultural areas $(\%)$ & 0.16 & 0.21 & -0.09 \\
\hline Forest, semi-natural areas $(\%)$ & -0.27 & -0.10 & 0.11 \\
\hline Wetlands (\%) & $0.76 * * *$ & -0.37 & -0.35 \\
\hline Water bodies $(\%)$ & $0.64 * *$ & -0.33 & -0.16 \\
\hline
\end{tabular}

$* P<0.05, * * P<0.01$ and $* * * P<0.001$

${ }^{\text {a }}$ Project size was calculated as the ratio between restoration length $(\mathrm{m})$ and restoration width $(\mathrm{m})$

${ }^{\mathrm{b}}$ PC1 was dominated by variables of the hydromorphological survey, e.g. channel geometry, river dynamics, connectivity and riverbed relief. PC2 represented hydromorphological variables at the scale of the mesohabitat, e.g. Shannon diversity for all channel features. For details of the hydromorphological variables, see Poppe et al. (this issue)

${ }^{c}$ Properties at the catchment scale represent land cover in the catchment

(Fig. 5). The response of species richness but not diversity of hydrophytes differed among restoration types with widening and flow restoration showing the largest and positive effect size (Kruskal-Wallis test, $H_{(3, n=18)}=8.51, P<0.05$ and $H_{(3, n=18)}=2.91$, $P>0.05$, respectively). Focusing on growth forms revealed that the differences in species richness among restoration types were mainly due to elodeids (Kruskal-Wallis test, $H_{(3, n=18)}=10.74, P<0.05$; Fig. 5). At sites with flow restoration as the main restoration measure, species richness and diversity of nymphaeids displayed positive effect sizes, whereas the effect sizes for this growth form were negative or zero at sites with remeandering and instream measures (Kruskal-Wallis test, species richness: $H_{(3, n=18)}=$ 11.19, $P<0.05$; diversity: $H_{(3, n=18)}=15.30$, $P<0.01$; Fig. 5).
Responses to river and catchment properties

The substrate and river type did not affect the species richness and diversity of hydrophytes if all growth forms were pooled (results not shown). At sites dominated by gravel, the species richness of elodeids showed a positive response and the proportion of the $\mathrm{C}$ strategy a negative response (elodeids: Sign test, $z=2.21, n=12, P<0.05 ; \mathrm{C}$ strategy: Sign test, $z=2.02, n=12, P<0.05$; Figs. 6B, 7A). The effect size of the proportion of the $C$ strategy in the communities differed from zero (negative response) also at mountain sites (Sign test, $z=2.21, n=12$, $P<0.05$ ) (Fig. 7C). The similarity in the results from restoration projects classified by substrate, river type and restoration types, respectively, is probably explained by the correlation of explanatory variables. 

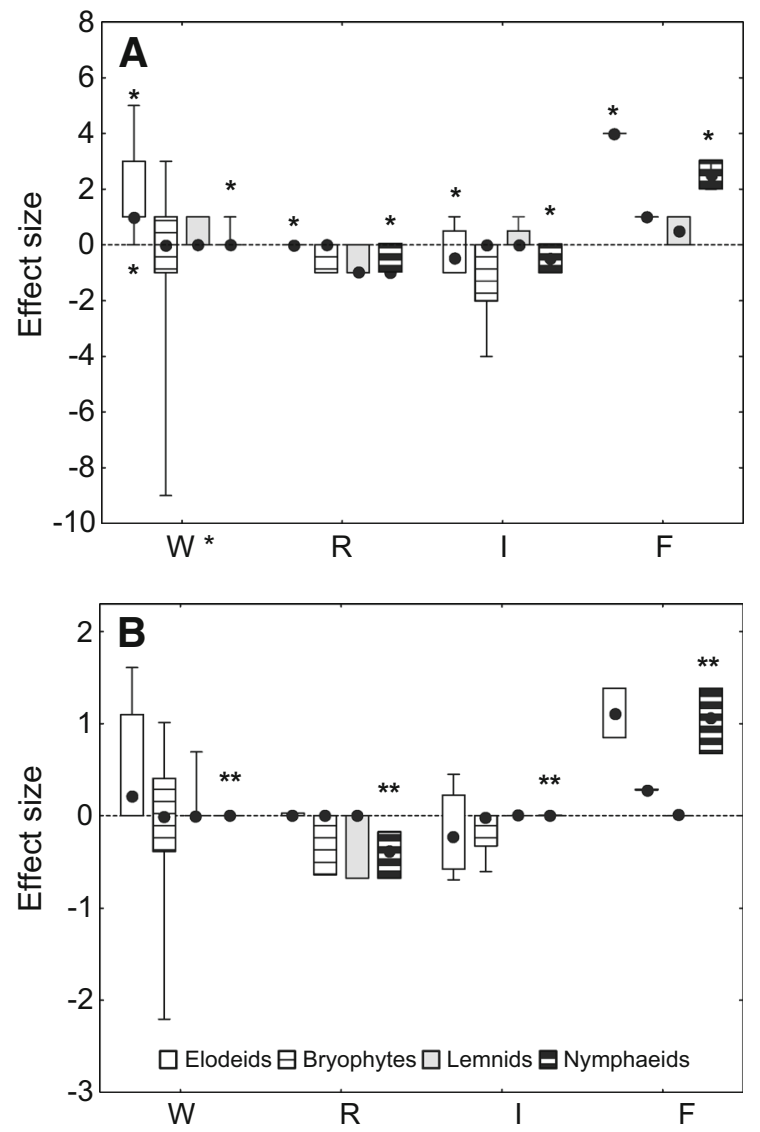

Fig. 5 Median effect size (difference between restored and degraded) of the species richness (A) and diversity (B) of elodeids, bryophytes, lemnids and nymphaeids at restoration sites, where widening ( $W n=9)$, remeandering $(R n=3)$, instream measures $(I n=4)$ or flow restoration $(F n=2)$ have been applied. Boxes represent 25 and 75 percentiles and whiskers 10 and 90 percentiles, respectively. Asterisks to the right of the different restoration types indicate significant differences $(P<0.05)$ among growth forms for the respective class. Asterisks below box-plots indicate that the effect size differed significantly from zero $(P<0.05)$. Asterisks above box-plots indicate that the effect size for a growth form differed between classes $(* P<0.05, * * P<0.01)$

For example, eight of the 10 widening restorations were performed in mountain rivers that had gravel as the dominating substrate (see also Table S1; Fig. 2). Neither species richness nor diversity of hydrophytes differed between substrate types (Kruskal-Wallis test, $H_{(1, n=20)}=0.06, P>0.05$ and $H_{(1, n=20)}=0.13$, $P>0.05$, respectively) or river types (Kruskal-Wallis test, $H_{(1, n=20)}=1.63, P>0.05$ and $H_{(1, n=20)}=$ $0.06, P>0.05$, respectively). However, differences between substrate and river types were revealed when
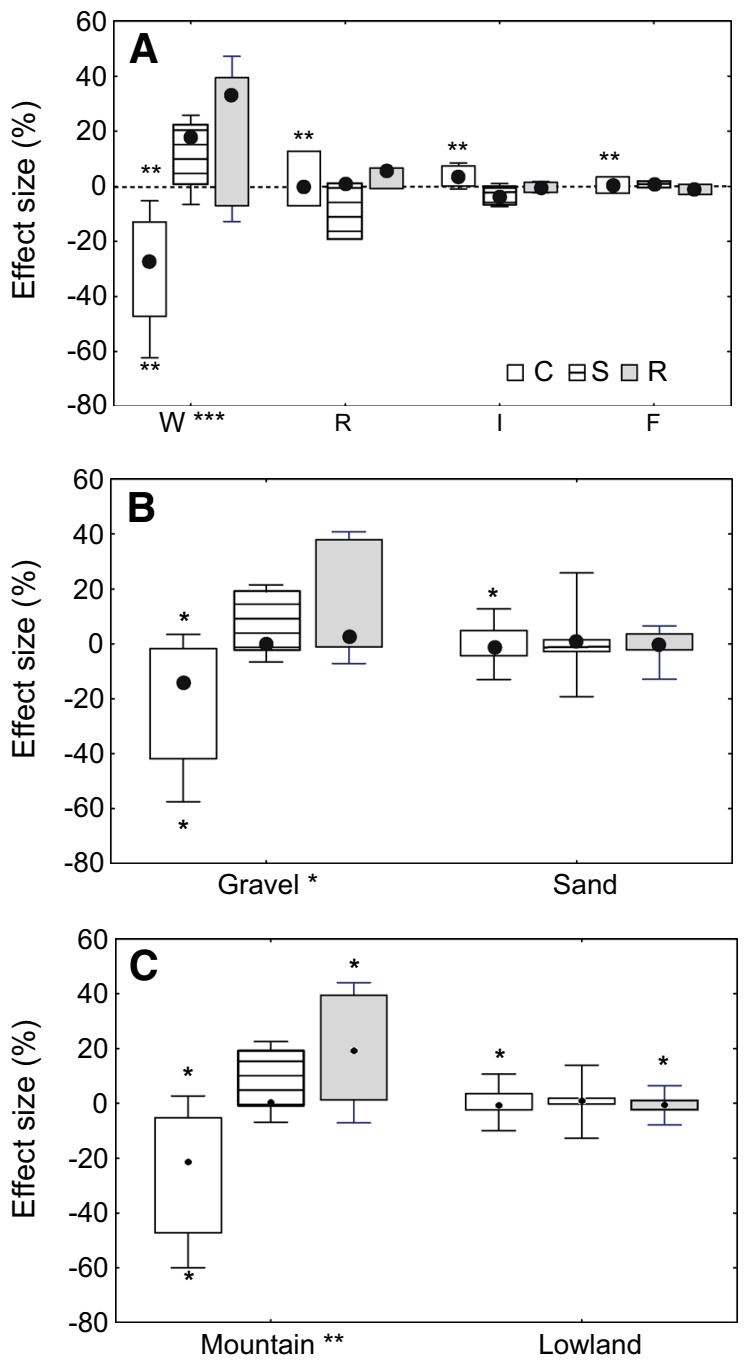

Fig. 6 Median effect size (difference between restored and degraded) of CSR plant strategies at $\mathbf{A}$ sites of different restoration measures ( $W$ widening $n=9, R$ remeandering $n=3, I$ instream measures $n=4, F$ flow restoration $n=2$ ), B restoration sites of different substrate type (gravel, $n=12$ and sand, $n=8$, respectively), and $\mathbf{C}$ mountain $(n=10)$ and lowland $(n=10)$ restoration sites. Boxes represent 25 and 75 percentiles and whiskers 10 and 90 percentiles, respectively. Asterisks to the right of the different class types indicate significant differences $(* P<0.05, * * P<0.01$, $* * * P<0.001)$ among strategies for the respective class. Asterisks below boxplots indicate that the effect size differed significantly from zero $(P<0.05)$. Asterisks above box-plots indicate that the effect size for a strategy differed between classes $(P<0.05)$

analysing growth forms and plant strategies. The response of species richness among growth forms differed at sites dominated by gravel (ANOVA $\left.\chi_{(n=12, d f=3)}^{2}=9.80, P<0.05\right)$ and at sites dominated 

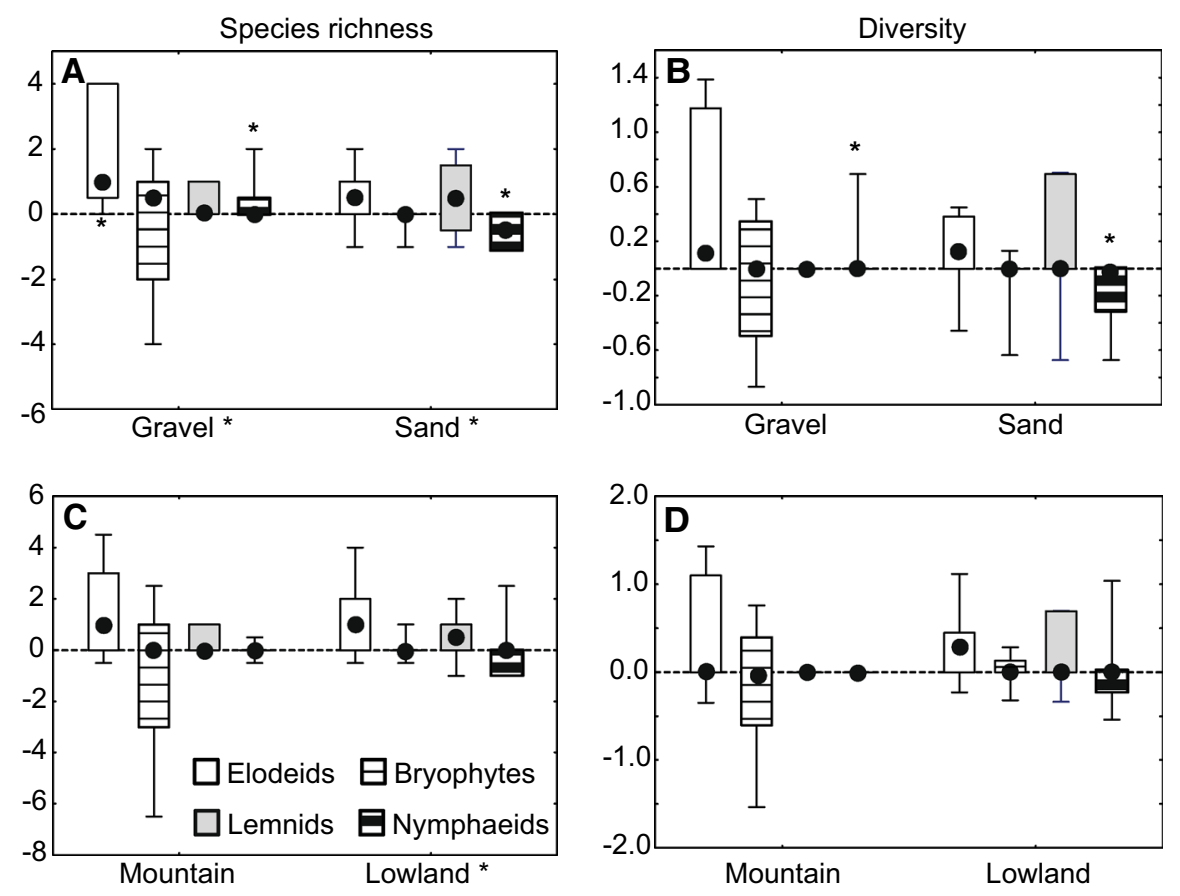

Fig. 7 Median effect size (difference between restored and degraded) of the species richness $(\mathbf{A}, \mathbf{C})$ and diversity $(\mathbf{B}, \mathbf{D})$ of hydrophyte growth forms in relation to substrate type (A, B gravel $n=12$, sand $n=8$ ) and river type (C, D mountain $n=10$, lowland $n=10$ ). Boxes represent 25 and 75 percentiles and whiskers 10 and 90 percentiles, respectively. Asterisks to the

by sand (ANOVA $\chi_{(n=8, d f=3)}^{2}=7.89, P<0.05$ ) (Fig. 7A, B). For nymphaeids, the effect size of species richness and diversity was significantly higher at sites dominated by gravel compared to those dominated by sand (Kruskal-Wallis test, $H_{(1, n=20)}=$ 5.23, $P<0.05$ and $H_{(1, n=20)}=4.36, P<0.05$, respectively) (Fig. 7A, B). The effect size of species richness differed among growth forms at lowland but not at mountain sites (ANOVA $\chi_{(n=10, d f=3)}^{2}=8.21$, $P<0.05$ and ANOVA $\chi_{(n=10, d f=3)}^{2}=7.08$, $P>0.05$, respectively) (Fig. 7C, D). The effect size of plant strategies showed similar patterns when classifying restoration sites according to substrate and river type (Fig. 6B, C). The proportion of competitive species decreased and that of stresstolerant and ruderal species increased at sites dominated by gravel and at mountain river sites (ANOVA $\chi_{(n=12, \quad d f=2)}^{2}=8.67, P<0.05$ and ANOVA $\left.\chi_{(n=10,}^{2} \quad d f=2\right)=11.40, P<0.01$, respectively; Fig. 6B, C). The proportion of competitive species in the communities differed between sites dominated by gravel and those dominated by sand (Kruskal-Wallis,

right of the substrate and river type, respectively, indicate significant differences $(P<0.05)$ among growth forms for the respective type. Asterisks below box-plots indicate that the effect size differed significantly from zero $(P<0.05)$. Asterisks above box-plots indicate that the effect size for a certain growth form differed between types $(P<0.05)$

$\left.H_{(1, n=20)}=4.34, P<0.05\right)$ and between mountain and lowland sites (Kruskal-Wallis test, $H_{(1, n=20)}=6.61, P<0.05$; Fig. 6B, C). Also the proportion of ruderal species in the plant communities differed between mountain and lowland sites (Kruskal-Wallis test, $H_{(1, n=20)}=3.86, P<0.05$; Fig. 6C).

The effect size of species richness and diversity of hydrophytes was not correlated with any of the predictor variables if all growth forms were pooled (Table 1). In contrast, the effect sizes of species richness and diversity of nymphaeids were positively correlated with slope, whereas those of lemnids were positively correlated with phosphate (Table 1). Among the hydromorphological variables, only properties characterizing the sites at the reach scale (i.e. PC1) correlated with effect size and only with the richness and diversity of elodeids (Table 1). Correlations between effect size and predictors were more pronounced for CSR strategies compared with growth forms (Tables 1,2). The effect size of the proportion of the C strategy was correlated with land cover, showing positive correlations with both the percentage 
cover of wetlands and water bodies in the catchment (Table 2). The effect size of the proportion of the $\mathrm{C}$ strategy was negatively correlated with altitude, but positively with the concentration of total organic carbon (TOC) (Table 2). The effect size of the proportion of the R strategy in the communities was negatively correlated to restoration length and all effect sizes were correlated with hydromorphological properties identified during the hydromorphological survey (Table 2). However, for the proportion of competitive species in the plant communities, the correlation was positive, whereas it was negative for the effect size of the proportion of stress-tolerant and ruderal species (Table 2). There were correlations for both the effect size of the proportion of competitive (negative) and stress-tolerant (positive) species with hydromorphological properties at the scale of the mesohabitat (Table 2).

\section{Discussion}

Eutrophication and hydromorphological degradation have been suggested as important drivers of macrophyte species loss in streams (Steffen et al., 2013). Restoration measures are conducted to reverse this process even though restoration measures per se may not guarantee ecosystem recovery (Palmer et al., 2010). Previous findings by Lorenz et al. (2012) showed that restoration generally increased species richness and diversity of hydrophytes. In contrast, our study revealed a complex relationship between restoration measures and the response of hydrophyte growth forms and plant strategies but not of hydrophytes per se. Surprisingly, responses of both growth forms and CSR plant strategies were more pronounced at small-scale compared to large-scale restoration sites. If we presume that the here-studied restoration measures represent 'ultimate goal' measures, the scale of restoration per se and probably the amount of invested resources are therefore not a good indicator of restoration success. However, it should be kept in mind that several of the predictor variables that explained the response of hydrophyte growth forms and plant strategies are interlinked, impeding the potential to identify single causes for identified responses. As our second PCA showed, project length and size were high in rivers located in catchments with a high percentage of agricultural areas. Hence, potential differences between for example small- and large-scale restoration projects might have been masked by land cover properties as also discussed below.

The studied restoration measures appeared to influence the response of the macrophyte communities, even though there is a risk of confounding effects from related predictor variables. Elodeids including species such as Ceratophyllum demersum L., Hippuris vulgaris L. and Potamogeton gramineus L. were besides bryophytes the most species-rich growth form. As expected, elodeids responded positively to widening and flow restoration measures. We need to consider though that flow restoration was performed in two projects only. Riverbed widening was the restoration measure with the most pronounced responses on all growth forms and proportion of CSR strategies. The removal of embankments and bank fixations were typical riverbed widening measures employed. One reason for the observed response could be that widening increases habitat area, heterogeneity and complexity. In contradiction to the habitat heterogeneity hypothesis (Simpson, 1949; MacArthur \& Wilson, 1967) but in line with the conclusions by Palmer et al. (2010), riverbed widening only increased species richness of elodeids, but not their diversity and not the species richness or diversity of the other growth forms. Widening created more shallow habitats with low flow velocity (Poppe et al., this issue), which might have favoured the establishment and persistence of elodeids compared to the fast flowing deeper degraded sections. Furthermore, widened channels are expected to have larger areas with direct sunlight (due to reduced shading from riparian trees) and low water depth, which probably positively affected hydrophyte growth as also noted by Makkay et al. (2008). Due to the importance of elodeid species as habitats and refuges for macroinvertebrates and fish (Strayer \& Malcom, 2007; Basińska et al., 2014), the positive effect of widening on elodeids could potentially also have cascading ecological effects. Instream measures in our study comprised, among others, bolder replacement and gravel additions to increase salmonid spawning areas. Elodeids generally have a broad tolerance for different substrate types, but several elodeids prefer soft substrates that may facilitate rooting (e.g. Dodkins et al., 2005).

The mechanisms driving the plant strategy responses at sites with widening as the main measure 
are unknown. We can suspect that widening creates more variable and unpredictable habitats that can be characterized by, for example, temporary flooding and increased grazing by waterfowl. Such variable conditions are probably less favorable for species with a purely competitive strategy such as Eupatorium cannabinum L., Glyceria maxima (Hartm.) Holmb, Lysimachia vulgaris L. and Typha latifolia L. Indeed, T. latifolia is known not to be able to cope with deep water (Grace \& Wetzel, 1982). The expected significant negative response of the proportion of the competitive plant strategy is therefore not surprising. It is however important to note that most studied species showed multiple and/or combined strategies (see Appendix-Supplementary Material), and we might therefore not expect straightforward responses of plant strategies.

The positive response of species richness and diversity of nymphaeids to flow restoration was unexpected, even though based on small sample size (see above). Increased flow and increased water level fluctuation are supposed to negatively affect nymphaeids (Bornette \& Puijalon, 2011; Mjelde et al., 2013). Many of the restoration sites studied here were characterized by multiple restoration measures even though a main restoration measure could be identified. For the nymphaeids, gravel and boulder additions might have created favorable low-flow habitats that overrule the potential negative effect of increased flow velocity at the reach scale. Also the creation of slowflowing microhabitats at sites with flow restoration might explain the response of nymphaeids.

Lorenz et al. (2012) found that the response of different growth forms to restoration differed between mountain and lowland streams, a result that we could not confirm. In contrast, we found that differences among growth forms were pronounced in lowland but not in mountain restoration sites. Our study supports the importance of stream type (lowland vs mountain) for the effect size of CSR plant strategies, however. In line with BaattrupPedersen and Riis (1999), we found that the effect sizes were substrate-dependent. In our study, river type and substrate type were, however, interlinked, since only four of the lowland sites are of the gravel type and at all other lowland sites, sand is dominating. In addition, it needs also to be considered that eight of the 10 widening restorations were performed in rivers that were mountain rivers and that had gravel as the dominating substrate. Hence, we need to be cautious when assigning identified responses to single factors. The effect of local and reach restoration measures might be overruled by upstream and non-restoration-related river characteristics (Lorenz \& Feld, 2013), which was, at least for plant strategies also supported by our study.

Time after restoration is an important predictor of macrophyte responses to restoration (Baattrup-Pedersen et al., 2000). Our study was performed on average 10 years (range 3-16 years) after the restorations. This time period was on average 5 years in Lorenz et al. (2012) who found significant restoration responses of several macrophyte growth forms. In our study, time after restoration did not affect the response of growth forms and plant strategies, whereas Kail et al. (2015) showed a decline in macrophyte response with increasing time since restoration. However, we cannot exclude time after restoration in combination with other factors as a confounding effect in our study. The species pool at the catchment scale is an important predictor of local plant species richness (Dynesius et al., 2004). If species richness is impoverished at the catchment scale, an increase in species richness associated with local restoration measures may be delayed and even fail as also predicted by the concepts of the ghost of land use past (sensu Harding et al., 1998) and/or an extinction debt (sensu Tilman et al., 1994).

The need for proper methods to assess the ecological and socio-economic effects of restoration projects has become a major task (Bernhardt et al., 2005). However, the ability to assess these effects is restricted by the lack of proper monitoring programs and assessment methods for different organism groups (Bernhardt et al., 2005). Also in our study, we did not monitor species responses along a temporal gradient ranging from prior to after the implementation of restoration measures. Instead, we used a space-fortime approach (comparing restored sites with degraded upstream sites). Future restoration projects should try assessing the true restoration effects by long-term monitoring of restoration sites. Indeed, time after restoration is the most important factor explaining restoration effects (Kail et al., 2015). In addition, restoration projects need to formulate target-group specific objectives. Otherwise, it will not be possible to evaluate true restoration success, but only, as in our study, restoration effects. 
Recently, the demand for functional perspectives of river restoration has been emphasized (Palmer et al., 2014). Indeed, our study showed that hydrophyte richness and diversity are poor indicators of the ecological effects of river restoration projects, whereas a focus on hydrophyte growth forms and strategies reveals actual restoration responses.

Acknowledgments We thank two anonymous reviewers and Jochem Kail for their valuable comments and Ulf Grandin for support with the statistical analyses. This study was supported by the project REFORM that received funding from the European Union's Seventh Programme for research, technological development and demonstration under Grant Agreement No. 282656.

Open Access This article is distributed under the terms of the Creative Commons Attribution 4.0 International License (http:// creativecommons.org/licenses/by/4.0/), which permits unrestricted use, distribution, and reproduction in any medium, provided you give appropriate credit to the original author(s) and the source, provide a link to the Creative Commons license, and indicate if changes were made.

\section{References}

Andersson, B., 1999. Vattenvegetation. Bedömningsgrunder för miljökvalitet. Sjöar och vattendrag Bakgrundsrapport 2. Biologiska parametrar. Rapport Naturvårdsverket (SNV) 4921.

Asaeda, T., L. Rajapakse \& M. Kanoh, 2010. Fine sediment retention as affected by annual shoot collapse: Sparganium erectum as an ecosystem engineer in a lowland stream. River Research and Applications 26(9): 1153-1169.

Baattrup-Pedersen, A. \& T. Riis, 1999. Macrophyte diversity and composition in relation to substratum characteristics in regulated and unregulated Danish streams. Freshwater Biology 42(2): 375-385.

Baattrup-Pedersen, A., T. Riis, H. O. Hansen \& N. Friberg, 2000. Restoration of a Danish headwater stream: shortterm changes in plant species abundance and composition. Aquatic Conservation: Marine and Freshwater Ecosystems 10(1): 13-23.

Basińska, A. M., M. Antczak, K. Świdnicki, V. E. J. Jassey \& N. Kuczyńska-Kippen, 2014. Habitat type as strongest predictor of the body size distribution of Chydorus sphaericus (O. F. Müller) in small water bodies. International Review of Hydrobiology 99(5): 382-392.

Bernhardt, E. S., M. A. Palmer, J. D. Allan, G. Alexander, K. Barnas, S. Brooks, J. Carr, S. Clayton, C. Dahm, J. Follstad-Shah, D. Galat, S. Gloss, P. Goodwin, D. Hart, B. Hassett, R. Jenkinson, S. Katz, G. M. Kondolf, P. S. Lake, R. Lave, J. L. Meyer, T. K. O’Donnell, L. Pagano, B. Powell \& E. Sudduth, 2005. Synthesizing U.S. river restoration efforts. Science 308(5722): 636-637.
Bornette, G. \& S. Puijalon, 2011. Response of aquatic plants to abiotic factors: a review. Aquatic Sciences 73: 1-14.

Craine, J. M., 2005. Reconciling plant strategy theories of Grime and Tilman. Journal of Ecology 93(6): 1041-1052.

Dodkins, I., B. Rippey \& P. Hale, 2005. An application of canonical correspondence analysis for developing ecological quality assessment metrics for river macrophytes. Freshwater Biology 50: 891-904.

Dynesius, M., R. Jansson, M. E. Johansson \& C. Nilsson, 2004. Intercontinental similarities in riparian-plant diversity and sensitivity to river regulation. Ecological Applications 14(1): 173-191.

Ecke, F. \& H. Rydin, 2000. Succession on a land uplift coast in relation to plant strategy theory. Annales Botanici Fennici 37(3): 163-171.

Gleick, P. H., 2003. Global freshwater resources: soft-path solutions for the $21 \mathrm{st}$ century. Science 302(5650): 1524-1528.

Grace, J. B. \& R. G. Wetzel, 1982. Niche differentiation between two rhizomatous plant species: Typha latifolia and Typha angustifolia. Canadian Journal of Botany 60: 46-57.

Grime, J. P., 1974. Vegetation classification by reference to strategies. Nature 250: 26-31.

Grime, J. P., 1977. Evidence for the existence of three primary strategies in plants and its relevance to ecological and evolutionary theory. The American Naturalist 111(982): 1169-1191.

Grime, J. P., 1979. Plant strategies and vegetation processes. Wiley, Chichester.

Grime, J. P., 1987. Dominant and Subordinate Components of Plant Communities: Implications for Succession, Stability and Diversity. In Gray, A. J., M. J. Crawley \& P. J. Edwards (eds), Colonization, Succession and Stability. Blackwell Scientific Publications, Oxford: 413-428.

Grime, J. P., 1988. The C-S-R Model of Primary Plant Strategies - Origins, Implications and Tests. In Gottlieb, L. D. \& S. K. Jain (eds), Plant Evolutionary Biology. Chapman \& Hall, London: 371-393.

Grime, J. P., J. G. Hodgson \& R. Hunt, 2007. Comparative Plant Ecology. A Functional Approach to Common British Species. Unwin Hyman, London.

Harding, J. S., E. F. Benfield, P. V. Bolstad, G. S. Helfman \& E. B. D. Jones, 1998. Stream biodiversity: the ghost of land use past. Proceedings of the National Academy of Sciences of the United States of America 95(25): 14843-14847.

Heck Jr., K. L. \& L. B. Crowder, 1991. Habitat Structure and Predator - Prey Interactions in Vegetated Aquatic Systems. In Bell, S., E. McCoy \& H. Mushinsky (eds), Habitat Structure. Population and Community Biology Series, Vol. 8. Springer, Dordrecht: 281-299.

Hellsten, S., 2001. Effects of lake water level regulation on aquatic macrophyte stands in northern Finland and options to predict these impacts under varying conditions. Acta Botanica Fennica 171: 1-47.

Kail, J., K. Brabec, M. Poppe \& K. Januschke, 2015. The effect of river restoration on fish, macroinvertebrates and aquatic macrophytes: a meta-analysis. Ecological Indicators 58: 311-321.

Klotz, S., I. Kühn \& W. Durka (eds), 2002. BIOLFLOR - Eine Datenbank zu biologisch-ökologischen Merkmalen der 
Gefäßpflanzen in Deutschland. Bundesamt für Naturschutz, Bonn.

Krebs, C. J., 1989. Ecological Methodology. Harper Collins Publishers, New York.

Lorenz, A. \& C. Feld, 2013. Upstream river morphology and riparian land use overrule local restoration effects on ecological status assessment. Hydrobiologia 704(1): 489-501.

Lorenz, A. W., T. Korte, A. Sundermann, K. Januschke \& P. Haase, 2012. Macrophytes respond to reach-scale river restorations. Journal of Applied Ecology 49(1): 202-212.

MacArthur, R. H. \& E. O. Wilson, 1967. The Theory of Island Biogeography. Princeton University Press, Princeton.

Mäkirinta, U., 1978. Ein neues ökomorphologisches Lebensformen-System der aquatischen Makrophyten. Phytocoenologia 4(4): 446-470.

Makkay, K., F. R. Pick \& L. Gillespie, 2008. Predicting diversity versus community composition of aquatic plants at the river scale. Aquatic Botany 88: 338-346.

Mjelde, M., S. Hellsten \& F. Ecke, 2013. A water level drawdown index for aquatic macrophytes in Nordic lakes. Hydrobiologia 704(1): 141-151.

Muhar, S., K. Januschke, J. Kail, M. Poppe, D. Hering \& A. D. Buijse, this issue. Evaluating good-practice cases for river restoration across Europe: context, methodological framework, selected results and recommendations. Hydrobiologia.

Murphy, K. J., B. Rørslett \& I. Springuel, 1990. Strategy analysis of submerged lake macrophyte communities: an international example. Aquatic Botany 36(4): 303-323.

O’Hare, J. M., M. T. O'Hare, A. M. Gurnell, P. M. Scarlett, T. O. M. Liffen \& C. McDonald, 2011. Influence of an ecosystem engineer, the emergent macrophyte Sparganium erectum, on seed trapping in lowland rivers and consequences for landform colonisation. Freshwater Biology 57:104-115.

Paillisson, J.-M. \& L. C. Marion, 2011. Water level fluctuations for managing excessive plant biomass in shallow lakes. Ecological Engineering 37: 241-247.

Palmer, M. A., H. L. Menninger \& E. Bernhardt, 2010. River restoration, habitat heterogeneity and biodiversity: a failure of theory or practice? Freshwater Biology 55: 205-222.
Palmer, M. A., K. L. Hondula \& B. J. Koch, 2014. Ecological restoration of streams and rivers: shifting strategies and shifting goals. Annual Review of Ecology, Evolution, and Systematics 45(1): 247-269.

Poppe, M., J. Kail, J. Aroviita, M. Stelmaszczyk, M. Giełczewski \& S. Muhar, this issue. Assessing restoration effects on hydromorphology in European mid-sized rivers by key hydromorphological parameters. Hydrobiologia. doi:10. 1007/s10750-015-2468-x.

Schaumburg, J., C. Schranz, J. Förster, A. Gutowski, G. Hofmann, P. Meilinger, S. Schneider \& U. Schmedtje, 2004. Ecological classification of macrophytes and phytobenthos for rivers in Germany according to the Water Framework Directive. Limnologica 34: 283-301.

Sharma, S., 1996. Applied Multivariate Techniques. Wiley, New York.

Simpson, E. H., 1949. Measurement of diversity. Nature 163: 688.

StatSoft, 2013. STATISTICA (data analysis software system). version 12.0. Statsoft Incorporation, Tulsa.

Steffen, K., T. Becker, W. Herr \& C. Leuschner, 2013. Diversity loss in the macrophyte vegetation of northwest German streams and rivers between the 1950s and 2010. Hydrobiologia 713(1): 1-17.

Strayer, D. L. \& H. M. Malcom, 2007. Submersed vegetation as habitat for invertebrates in the Hudson River estuary. Estuaries and Coasts 30(2): 253-264.

Tabacchi, E., D. L. Correll, R. Hauer, G. Pinay, A.-M. PlantyTabacchi \& R. C. Wissmar, 1998. Development, maintenance and role of riparian vegetation in the river landscape. Freshwater Biology 40(3): 497-516.

ter Braak, C. J. F. \& P. Smilaur, 2002. CANOCO for Windows Version 4.5. Biometrics - Plant Research International, Wageningen.

Tilman, D., R. M. May, C. L. Lehman \& M. A. Nowak, 1994. Habitat destruction and the extinction debt. Nature 371(6492): 65-66.

Zar, J. H., 1996. Biostatistical Analysis. Prentice-Hall Inc., London. 